\title{
Las identidades de la crónica: hibridez, polisemia y ecos históricos en un género entre la literatura y el periodismo ${ }^{1}$
}

\section{Dolors Palau-Sampio²}

Recibido: 2016-12-01

Enviado a pares: 2017-01-11
Aprobado por pares: 2017-01-12

Aceptado: 2017-02-20

DOI: $10.5294 /$ pacla.2018.21.1.9

Para citar este artículo / to reference this article / para citar este artigo Palau-Sampio, D. (2018). Las identidades de la crónica: hibridez, polisemia y ecos históricos en un género entre la literatura y el periodismo. Palabra Clave, 21(1), 191-218. DOI: 10.5294/pacla.2018.21.1.9

\section{Resumen}

Como todos los conceptos de frontera, el de crónica no resulta precisamente cristalino, en particular a la hora de encontrar una definición que despierte consenso o adquiera una cierta universalidad. Tratar de definir sus contornos constituye el objetivo de este artículo, que plantea un recorrido histórico para tratar de entender los diferentes matices que encierra. Bajo el paraguas de un término entre la literatura y el periodismo, híbrido y polisémico como crónica, se identifican tres tipos producciones. El análisis de las variedades periodísticas permite reconocer, en primer lugar, una modalidad ligada a la actualidad, de carácter más breve; en segundo

\footnotetext{
1 Este proyecto ha recibido financiación del programa de investigación e innovación Horizonte 2020 de la Unión Europea en virtud del acuerdo de subvención Marie Skłodowska-Curie no 645666

2 orcid.org/0000-0001-9051-0239. Universidad de Valencia. España. dolors.palau@uv.es
} 
lugar, producciones de largo aliento, exigentes en términos de investigación y acceso a las fuentes; y en tercer lugar, una variedad de textos de autor, de carácter más ensayístico, que toma el elemento informativo apenas como punto de partida. Con esta distinción se pretende desentrañar la confusión que despierta el género periodístico, puesto que en España crónica responde a la primera modalidad, mientras que en algunos países latinoamericanos conviven las distintas acepciones bajo la misma denominación.

\section{Palabras clave}

Crónica; géneros; periodismo; narración; literatura (Fuente: Tesauro de la Unesco). 


\section{Identities of the Chronicle: Hybridity, Polysemy and Historical Echoes in a Genre between Literature and Journalism}

\section{Abstract}

As with all border concepts, the concept of chronicle is not exactly crystal clear, particularly when looking for a definition that generates consensus or that acquires some kind of universality. In this paper, we attempt to define it by making a historical review in order to try and understand its different nuances. A chronicle is a hybrid and polysemic term that is somewhere between literature and journalism. After analyzing the journalistic varieties, we were able to identify three types of productions: first, a modality linked to present times, which is shorter; second, long-winded productions, which are demanding in terms of research and access to sources; and third, a variety of author's texts of a more essayistic nature, which uses the informative element only as a starting point. With this distinction, our goal is to unravel the confusion generated by the journalistic genre, since a chronicle is the first modality in Spain, while in some Latin American countries the different meanings coexist under the same name.

\section{Keywords}

Chronicle; genre; journalism; narration; literature (Source: Unesco Thesaurus). 


\section{As identidades da crônica: hibridez, polissemia e ecos históricos em um gênero entre a literatura e 0 jornalismo}

\section{Resumo}

Como todos os conceitos de fronteira, o conceito de crônica não é precisamente cristalino, particularmente na hora de encontrar uma definição que desperte consenso ou que adquira uma certa universalidade. Tentar definir os seus contornos constitui o objetivo deste artigo, que sugere um percurso histórico para tentar entender os diferentes matizes nele contidos. Sob a guarda de um termo entre a literatura e o jornalismo, híbrido e polissêmico como crônica, identificam-se três tipos produções. A análise das variedades jornalísticas permite reconhecer, em primeiro lugar, uma modalidade ligada ao momento atual, de caráter mais breve; em segundo lugar, produções mais prolongadas, exigentes em termos de pesquisa e acesso às fontes; e em terceiro lugar, uma variedade de textos de autor, de carácter más ensaístico, que toma o elemento informativo apenas como ponto de partida. Com esta distinção se pretende desentranhar a confusão suscitada pelo gênero jornalístico, já que na Espanha a crônica responde à primeira modalidade, enquanto que em alguns países latino-americanos as diferentes acepções convivem sob a mesma denominação.

\section{Palavras-chave}

Crônica; gêneros; jornalismo; narração; literatura (Fonte: Tesauro da Unesco). 


\section{Introducción}

El concepto crónica ha acabado por ensanchar sus fronteras hasta referir una heterogénea variedad de producciones. En los últimos años, esta etiqueta se ha transformado en la marca de una modalidad periodística de largo aliento desarrollada en distintos países latinoamericanos, un fenómeno emergente al que algunas voces se refieren como boom de la crónica latinoamericana. Más allá del marketing o el alcance del término, presente en el título de dos compilaciones recientes, Antología de crónica latinoamericana actual (Jaramillo, 2012) o Mejor que ficción: crónicas ejemplares (Carrión, 2012), esta denominación no acaba de convencer siquiera a algunos de sus máximos embajadores, como los periodistas argentinos Martín Caparrós (2015) o Leila Guerriero (entrevista personal, 31 de marzo de 2015), que prefiere hablar de "periodismo narrativo". Desde el ámbito académico, la designación plantea un reto importante. Algunos autores critican la confusión que entraña y apelan a un uso apropiado y pertinente (Chillón, 2014,pp. 408-409), destacan la necesidad de revisar el paradigma genérico (Montes, 2013, p. 11) o de ampliar los contornos de la crónica para abarcar textos que "no pretenden desentrañar una verdad ni contar historias, sólo intentan establecer relaciones a fin de organizar imágenes, perspectivas y afectos" (Bernabé, 2010, p. 9). Otros investigadores, en cambio, abogan por fórmulas alternativas como "periodismo narrativo" (Herrscher, 2012) o "estilo narrativo" (Hoyos, 2003a).

El objetivo de este artículo es analizar la variedad de significados que se atribuyen actualmente al término crónica, explorar su genealogía y proponer una clasificación, con criterios que permitan distinguir entre producciones periodísticas que, a pesar de compartir algunas similitudes, resultan divergentes - en ocasiones contrapuestas - , en un arco que englobaría desde artículos ensayísticos de formato breve o textos de actualidad fundamentados en la interpretación y especialización del periodista, a otros de largo aliento basados en una investigación exhaustiva. Las referencias a la hibridez y polisemia de la palabra crónica han sido destacadas por varios autores, tanto desde el ámbito de la literatura (Ramos, 1989; Oviedo, 1991; González, 1995, Rotker, 2005) como del periodismo (Marques de Melo, 
1992; Vallejo, 1997; Samper, 2001; Hoyos, 2003b; Parratt, 2008; Callegaro, Lago, Quadrini y Bragazzi, 2011; Darrigrandi, 2013; Poblete, 2013, 2014). No obstante, más allá de las constataciones, se hace necesaria una revisión de las raíces de esta polisemia, desde el peso del referente histórico a la hibridez entre la literatura y el periodismo o la influencia de las tradiciones y evoluciones dentro de este último campo.

\section{El polo histórico: testimoniar la extrañeza y explorar los márgenes}

El término crónica viene acompañado de resonancias históricas, no solo a las llamadas crónicas de Indias — sobre la llegada y colonización del nuevo continente - o las medievales (Alvar, Mainer y Navarro, 1997), sino al precedente de estas en la Grecia del siglo $\mathrm{V}$ a. C, de las que toma su etimología3 (Kapuscinski, 2006; Chillón, 2014).

La crónica apareció como "una forma embrionaria de la historiografía” (Gil González, 2004), como "la herramienta narrativa más adecuada para que una persona intelectualmente relevante relatara a un determinado público lo que sucedía en un lugar”. Por ello, sostiene Gil González, "ha sido uno de los mecanismos más idóneos que se ha manejado para la transmisión del conocimiento histórico a las generaciones futuras" (2004). Sin embargo, las crónicas estaban lejos de resultar un espejo incontrovertible. Bernal afirma que "no se limitan al relato objetivo de los hechos de actualidad, sino que la pura información convive con la interpretación hasta, en ocasiones, con la propaganda” (1997, pp. 10-11). Cabrol (2009) pone el acento en la "forma de narrar hechos reales mixturados con fábulas y mitos que provienen del mundo grecolatino, leyendas medievales y novelas de caballería", de la mano de soldados, clérigos, eruditos o navegantes. "El cronista testigo modifica la textualización y la otredad se diluye en el discurso [... ] Historias verdaderas, historias fingidas se mezclan para dar cuenta de la desmesura de lo nuevo para el lector europeo" (2009).

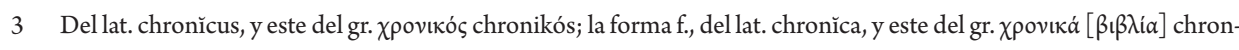
iká [biblía] “[libros] que siguen el orden del tiempo”, según la definición de la Real Academia Española. 
A pesar del carácter fundacional en la literatura latinoamericana (Oviedo, 1991, pp. 71-72), la principal finalidad de las crónicas de Indias no era literaria sino documental, destinada a "hacer referencia a —o ser- la historia de un nuevo espacio” (Mateo, 2001, p. 13). Como Kapuscinski (2006), Gil González (2004) ve en el cronista a una especie de precursor del periodista, que selecciona, interpreta y narra unos hechos. De estos orígenes, pervive en la crónica periodística la idea de "relato que secuencia los acontecimientos según un orden cronológico", cuyo autor es un "testigo privilegiado de los hechos", "encargado de estructurar los sucesos".

Cabrol (2009) subraya otra circunstancia que asemeja el relato de Indias al de los periodistas: la conexión a la actualidad, ya que se trata de textos escritos de forma inmediata o con escasa diferencia de tiempo en el momento que narran. A ello cabe añadir el carácter de un cronista "que relata con la referencialidad y la cosmovisión europea de la época medioeval-renacentista y con una necesidad informativa que se torna expresiva en las lecturas actuales" (p. 1), que deja su impronta, un punto de vista particular (Hernández, 2008, p. 216), una circunstancia que las acerca a la forma de entender el género en la actualidad. El cronista se erige como "observador crítico frente a la extrañeza que provoca la historia que se documenta" y de la que "da testimonio" (Cabrol, 2009, p. 3), una perplejidad que comparte el periodista, como sostiene Caparrós:

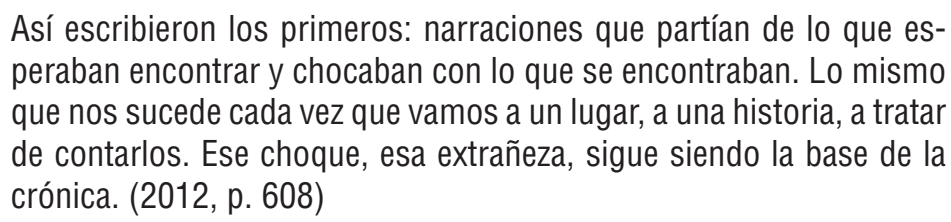

Si en un primer momento se impuso la visión de los conquistadores, la crónica también fue capaz de registrar, con posterioridad, la "visión de los vencidos" o "el reverso de la conquista", el "heroico esfuerzo de los pueblos dominados [...] para dar testimonio de sí mismos y sobrevivir así en la memoria" (Oviedo, 1991, p. 99). Reguillo (2007, p. 46) reclama para la crónica periodística la tarea de visibilizar y "recuperar" la voz y la mirada de personajes "liminales": "Sin resolver la cuestión del acceso a un lugar 
legítimo de enunciación, fisura el monopolio de la voz única para romper el silencio de personas, situaciones, espacios, normalmente condenados a la oscuridad del silencio. La investigadora incide en que "la crónica no es un género inocente, una escritura 'neutra', en tanto que aspira a representar lo no representado y lo no representable en el concierto de los múltiples relatos para contar el mundo" (p. 49). También Sefchovich (2015, pp. 9-10) subraya este aspecto, mientras Cairati (2013) destaca su papel como el territorio de la subalternidad.

Falbo estima que el exotismo de los cronistas del pasado ha mudado a mundos cercanos desdibujados "por los procesos de segregación y las distintas formas de violencia, desplazamiento y/o exclusión" y explica que "al patrón de cronicar para testimoniar unos hechos, cierta crónica en América Latina evolucionó hacia una escritura como voluntad de intervención que interroga en presente la historicidad de nuestra vida colectiva" (2007, p. 14).

\section{El polo literario: resonancias modernistas}

La idea de crónica como concepto híbrido representa un lugar común en las reflexiones sobre este género a mitad de camino entre periodismo y literatura, "un sitio discursivo de fronteras abiertas y porosas" (Bernabé, 2010, p. 6). Junto al reconocimiento de su ubicación entre dos orillas, para entender una parte de las producciones que responden al nombre de crónica resulta imprescindible deshacer el camino que lleva a su conexión con la crónica modernista. Si en las de Indias prima la vocación historiográfica, aquí toma fuerza el componente literario, canalizado a través de la prensa.

La crónica modernista nace de la tensión entre ambos polos, de la particular relación entre periodismo y literatura a finales del siglo XIX, y ello condiciona de manera importante la autoría y el carácter de las producciones. ${ }^{4}$ En este contexto, emerge una nueva tipología de escritor que "reconoce en el mercado, no sólo un medio de subsistencia, sino la posibilidad de fundar un nuevo lugar de enunciación y de adquirir cierta le-

4 Sirkó (1975) advierte que el cronista tiene que adaptarse al nivel del público, al espacio de la página, a una "inusitada pluralidad de temas" y a unos plazos de entrega, lo cual se traduce en "una seria limitación al desarrollo artístico de un escritor" (citado por Mateo, 2001, p. 31). 
gitimidad intelectual", una posición "profesionalista" que "se distancia del escritor estrictamente mercantil del periódico" (del reporter consagrado a la noticia y ajeno a la expresión), pero también de "los aparatos exclusivos, tradicionales, de la república de las letras” (Ramos, 1989, p. 86). Las producciones difundidas a través de la prensa constituyen "el modo más eficaz de subsistencia mediante la escritura" (p. 90), al tiempo que representan, en autores como José Martí, una especie de "trabajo 'alienado' en la mesa de comercio" (p. 88).

Rotker (2005, p. 104) presenta la crónica modernista como "un género nuevo donde comunicación y creación, información, presiones externas y arte parecían reñidas", pero terminaron encontrando "su espacio de resolución". ${ }^{5} \mathrm{La}$ investigadora pone el acento en lo que representa de ruptura del canon literario, de laboratorio para ensayar el estilo de escritura cuando plantea:

¿Qué es lo que hace que estos textos informativos, noticiosos, sean obras de arte? [...] proviene de la voluntad de escritura, del cómo se ha verbalizado su discurso, del cómo prevalece el arte verbal en la transmisión de un mensaje referencial. (p. 113)

Para Ramos, "la crónica fue, paradójicamente, una condición de posibilidad de la modernización poética", ya que "en oposición al periódico, en el periódico, el sujeto literario se autoconsolida, precisamente al confrontar las zonas 'antiestéticas' del periodismo y la 'cultura de masas": "constituye, más que una 'hibridez' desjerarquizada, un campo de lucha entre diferentes sujetos o autoridades" (1989, p. 91).

Es en el ámbito expresivo, más que en el propiamente periodístico, desde el punto de vista de la producción, donde la aportación de la crónica modernista se hace más evidente. De hecho, Rotker (2005, p. 109) incide en que "se distancia de la 'externidad' de las descripciones, defendiendo el yo del sujeto literario y el derecho a la subjetividad" en un contexto — la última década del XIX — en que se vivía un auge particular de

5 A pesar de sus colaboraciones en prensa, numerosos autores "con frecuencia representaban el periodismo como una de las causas fundamentales de la 'crisis' de la literatura” (Ramos, 1989, pp. 101-102). 
la objetividad, con periodistas que "se consideraban a sí mismos como científicos o artistas del realismo", con la figura de reporter concentrado en los hechos.

La crónica modernista se ubica en una encrucijada entre el ámbito periodístico que exige referencialidad y actualidad, y el literario, que cuestiona su carácter factual. En ella, más allá del "alto grado de referencialidad y actualidad (la noticia)" imprescindible para publicarse en prensa, señala Rotker (2005, p. 101), "los literatos recurren a la estilización para diferenciarse del mero reporter, para que se note el sujeto literario y específico que ha producido la crónica". Es la opción de José Martí, la gran figura de la crónica modernista, en "El terremoto de Charleston" (1886), escrito a través de referencias tomadas de diversas publicaciones. "Él no estuvo en Charleston personalmente, aunque el presente y el detalle de su escritura tienen la vivacidad de un testigo presencial”, señala $\operatorname{Rotker~(1993,~p.~160).~}$ Su misión se centra en "literaturizar los datos extraídos" (p. 160). No en vano, como afirma Martí en su crónica sobre el terremoto, "Decirlo es verlo", antes de iniciar una detallada descripción sobre cómo se sintió el fenómeno sísmico (p. 165).

Desde la ortodoxia periodística, esta práctica — tomar datos de otros medios sin explicitarlo, para hacer una reelaboración literaria- contravendría los principios básicos de la profesión. Como también la que refiere Rotker en el prólogo de las Crónicas de Martí, al apuntar que estos textos "extraen de su cualidad literaria recursos como la ficcionalización, la analogía y el simbolismo" (1993, p. 27). González incide en que "aprovecharon la vaguedad genérica de la crónica para insertar textos puramente ficcionales dentro del espacio que les brindaba el periodismo" (1995, pp. 158-159) y destaca que encontraron en este género "el espacio y el sustento" de la prensa "para ir aguzando sus armas literarias". Así, los autores modernistas desarrollaron "un discurso decorativo y frívolo, pletórico de vívidas metáforas y de alusiones literarias y culturales, con el que implícitamente desafiaban las exigencias informativas y utilitarias del periodismo" (pp. 156-157). 
Para Mateo, "muchas crónicas de esta época se avienen mejor a las características de un discurso ensayístico que a los imperativos de la crónica” (2001, p. 28), hasta el punto de que Jiménez se muestra partidario de diferenciar, en la obra de Martí, entre los textos que se considerarían propiamente crónica y los ensayísticos (1995, p. 333). Si el contexto periodístico obliga a tratar sucesos recientes, la hibridez del género facilita "que los cronistas muestren su subjetividad, su estilo personal y una mayor variedad temática", de modo que "a veces la noticia es solo el punto de partida o mero pretexto para introducir digresiones sobre los asuntos más diversos" (Mateo, 2001, pp. 29-30).

Ramos subraya que "la crónica surge como una vitrina de la vida moderna” (1989, p. 90). Como en las de Indias, las modernistas permiten descifrar los cambios — en la sociedad de fines del siglo XIX—, se convierten en la forma expresiva para canalizar "la experiencia de una temporalidad vertiginosa y fragmentaria” (p. 112), de ahí que Martí las denomine "pequeñas obras fúlgidas” (Rotker, 1993, pp. 28-29). La crónica aparece como una "mediación entre el sujeto privado y la ciudad" y, entre ambos, el cronista-flanêur emerge como el punto de conexión (Ramos, 1989, p. 129). A esta forma de transitar el extrañamiento, se suma la voluntad de mostrar la autoridad "en sus dos sentidos de sujeto del poder y de productor de textos" (Oviedo, 1991, p. 74). Para los modernistas, "representar la ciudad" no fue "un mero ejercicio de registro o documentación del cambio", sino "un modo de dominarla, de reterritorializarla, no siempre desde afuera del poder" (Ramos, 1989, p. 123).

Las influencias modernistas están presentes en una corriente de estudio de la crónica actual que pone el acento en lo literario frente a lo periodístico. Así, Bernabé establece una distinción clara entre "periodistas que recurren a la literatura para proveerse de técnicas narrativas con el propósito de relatar con eficacia una serie de historias reales" y "autores de literatura que experimentan con la forma breve de la crónica para experimentar con las relaciones entre ficción y realidad", "registros que conviven en tensión aunque las separaciones se vuelven cada vez más borrosas y confusas” (2010, p. 9). "Lejos de la crónica tal como se la entiende y practica en las 
actuales escuelas de periodismo" (p. 4), Bernabé cuestiona las retóricas del realismo ingenuo que "sucumben a una propuesta mimética" (citado por Cristoff, 2009) y aboga por las "crónicas de autor" (p. 10), frente a los textos que imitan un modelo previsible y "reproducible". Centra la atención en la crónica "como una forma narrativa que manifiesta un deseo de lo real y como un producto de la industria cultural altamente estetizado" (Bernabé, 2014, pp. 121-122).

En la reflexión de Bernabé, lo periodístico se convierte en una categoría menor, así como en la de Cristoff, que apuesta por el valor estético y se muestra crítica con una crónica entendida como "narrativa escrita bajo los preceptos de los manuales de ética periodística a la que luego se debe edulcorar con literatura” (2014, p. 11). Esta tesis preside la antología Idea crónica (Cristoff, 2006), con una quincena de obras que se mueven entre el ensayo, el relato de viaje, el diario íntimo, la autobiografía o la entrevista. Entre los autores incluidos está la periodista, ensayista y crítica cultural argentina María Moreno, que se alinea con un modelo de crónica que entroncaría más con la modernista que con las producciones en alza en los últimos años. Esta filosofía se refleja en su obra Banco a la sombra (2007), sobre las plazas de Buenos Aires y otras ciudades del mundo, en la que el espacio de atención no tiene que haber sido necesariamente visitado, en la línea de Martí.

\section{Propuestas de clasificación}

Aunque sin vocación de categorizar, tanto Cristoff (2009) como Moreno (citado por Viola, 2010) han planteado clasificaciones de la crónica que, en esencia, coinciden con la distinción de Bernabé entre crónica periodística y literaria. Ambas se refieren a la primera en relación con el nuevo periodismo. Mientras Cristoff habla de relatos "a trasmano de los mitos de los grandes medios" y de la que apenas salen bien parados algunos nombres, Moreno concreta un poco más y divide dos categorías en función de esta solvencia:

6 "Presentación de algún personaje raro, puede ser under o marginal, o la focalización de un grupo social particular para relatar sus historias y diseñar sus perfiles a partir de entrevistas de profundidad mientras se desgrana sobre la relación entre el caso particular y los procesos sociales en general” (2010, pp. 7-8). En términos similares, se expresa Moreno (2010): "La crónica hoy parece poner en escena la fuerza del objeto en sí, lo más heavy, lo más raro y exótico, mientras que el lenguaje es meramente instrumental o de un realismo ramplón”. 
1. el "nuevo periodismo", el texto periodístico "con énfasis en la narración", que se limita a "expropiar los recursos retóricos de la narrativa realista", y 2. la "no ficción", que "implica un cierto modelo judicial de investigación aspirando a otra sentencia que la oficial" y en la que se englobarían desde los textos de Truman Capote, Rodolfo Walsh o Cristian Alarcón, "donde el cronista ocupa el lugar del juez". En relación con la crónica literaria, Cristoff señala que está "estrechamente ligada a la tradición de la crónica modernista latinoamericana", mientras que Moreno se refiere a ella como "la crónica", de la que señala que "si bien mantiene un nexo con 'los hechos' está menos regida por 'la prueba". Añade que la exigencia de reportear in situ es "relativamente contemporánea": "Un José Martí no iba a cubrir la noticia, escribía a partir de lo que leía en el periódico. Un Fray Mocho escribía 'En el mar la austral' sin haber viajado" (en Viola, 2010).

Cristoff identifica la crónica de vocación literaria con "formas breves, cercanas al ensayo o a la pieza literaria", que tratan cuestiones "entre los márgenes, los fenómenos de la cultura popular y los temas engañosamente menores", en tono irónico, que en una línea más próxima a la de Marques de Melo (1992) presenta la crónica en el contexto luso-brasileño, en el ámbito del articulismo de opinión, y que en el ámbito español vendría a representar la tradición del cuadro o el artículo de costumbres, y cita como "referentes indiscutibles” a Carlos Monsiváis, Edgardo Rodríguez o María Moreno (2010), un catálogo al que se suman Pedro Lemebel o Sergio Chejfec, que "se inscriben en la serie literaria inaugurada hacia fines del siglo diecinueve" (Bernabé, 2010, p. 9), en un arco de continuidad que abarca a autores como Roberto Arlt, Teófilo Cid, Clarice Lispector, Salvador Novo, Alfonsina Storni o Daniel de la Vega (Darrigrandi, 2013; Poblete, 2013, 2014). O los cronistas de la "época dorada" colombiana (1910-1960), cultivadores de una modalidad que combina los estilos narrativo y ensayístico y que, a diferencia de la informativa, se desentiende de lo temporal (Vallejo, 1997), un "ejercicio de estilo" en el que predomina la función estética sobre la información y el análisis (Vallejo, 2006). Samper subraya el nexo con la voz

7 Cristoff (2009) incluye una tercera categoría, la que sigue la tradición europea del relato de viaje, crónicas de largo aliento en forma de libro: "Se diferencian del relato de viaje tradicional porque el traslado ya no está asociado a la novedad por descubrir sino a un tema narrativo por indagar". 
del autor, como "un flujo narrativo que recuerda un poco a los cuentos de la abuela", a menudo con carácter moralizador (2001, p. 16).

Esta línea de investigación y reflexión sobre la crónica, de vocación literaria, fuerza los goznes de una definición del género que pueda ser aceptada por aquellos que la transitan desde una orilla con énfasis más periodístico. $\mathrm{Su}$ argumentario pivota sobre tres ideas: 1. la crítica al pomposo dispositivo de referencialidad periodística ${ }^{8}$ frente a la liviana carga del cronista que no necesita desplazarse a los lugares o consultar y citar sus fuentes; 2 . la vocación de trascender el mero hecho, en la línea de un avezado observador de las transformaciones más que de un reporter que da cuenta del hecho en sí; y 3) la reprobación del oportunismo y la escasa calidad de algunos textos adscritos a la etiqueta de crónicas. ${ }^{910}$

\section{El polo periodístico: polisemia y clasificación de géneros}

A la hibridez del género y el resonar de ecos de una larga historia se suma, desde el campo periodístico, una polisemia que contribuye a arrojar dosis complementarias de confusión sobre las producciones etiquetadas como crónica. "La crónica periodística es uno de los géneros más difíciles de definir porque comparte facetas de otros géneros y su significado varía sustancialmente de un país a otro" (Parratt, 2008, p. 131). Gil González (2004) atribuye la "brumosidad de sus fronteras" a "los usos que de ella ha hecho la profesión”.

8 "Mientras en los cronistas de fines del XlX y XX se trataba de hacer algo grande de lo nimio, los nuevos cronistas quieren objetos que tengan peso en sí: narcotráfico por sus protagonistas, las putas niñas, los pobres 'exóticos'. En la biblioteca latinoamericana y del Caribe la crónica es un laboratorio de escritura, donde el dato periodístico está supeditado al clima, los personajes y los diálogos literarios y sobre todo cumple una función política” (Moreno, en Viola, 2010).

9 "La política del mercado que hoy reinventa la crónica recoge la herencia del boom latinoamericano en cuanto a mercar pintoresquismo. Entonces se corre el peligro de leer las complejas operaciones que hace un Monsiváis o un Lemebel en clave color local [?]. Creo que hoy se llama crónica a productos muy diversos. Se llama crónica a la literatura hecha en los periódicos pero también a los productos del nuevo periodismo que hacen creer en la posibilidad de representar el objeto en sí, entonces recogen grandes temas como el narco, Oriente, los freaks [?]” (Moreno, citado por Cristoff, 2009).

10 "Hoy sorprende que a muchos [... el mercado los califique de 'cronistas' para adjudicarles el sello de lo narrativo literario cuando en realidad ejercen un realismo ramplón en donde se trataría de representar el objeto en sí, con el estilo del inventario, o retuercen la lengua para ver si cae una metáfora, hasta el ripio o el kitsch inconsciente. Porque Raab no redactaba: escribía” (Moreno, 2010). 
Si trazar los márgenes entre lo literario y lo periodístico se presenta como tarea difícil, más si cabe es tratar de graduar los cambios dentro de este último ámbito, que engloba dos producciones — crónica y reportajeen las que la referencialidad tiene un alto grado de importancia, así como la mirada y la interpretación, pero en las que varía la prioridad de la actualidad, la presencia de fuentes o el alcance de la investigación.

\section{Crónica y reportaje}

La clasificación en géneros de las producciones periodísticas —iniciada por Kayser en la década de 1950 — no resulta ajena a las disputas. Parratt (2008, pp. 11-12) atribuye la confusión a que el periodismo no es una "ciencia exacta” fundada sobre esquemas rígidos e inamovibles, a la influencia del factor "espacio-temporal" (cómo evolucionan y se entienden en diferentes países y medios) y a la intervención de un "componente subjetivo innegable". La tipología latina ubica la crónica en los macrogéneros de interpretación, un estadio intermedio entre información y opinión, a partir de la distinción anglosajona entre stories y comments (Martínez Albertos, 1983). Este macrogénero incluye también la entrevista, el reportaje y el perfil, modalidades que representan un segundo nivel de lectura de la actualidad. Desde el punto de vista expresivo, implica una mayor libertad para estructurar la información, usar recursos estilísticos o exteriorizar una interpretación que debe ajustarse a los datos.

Aunque los cuatro géneros cuentan con entidad e historia propias, diversos autores han incidido en las similitudes entre el reportaje y la crónica, en particular la referencia al carácter interpretativo y a las posibilidades que brindan al autor. Martínez Albertos considera la crónica como "una información interpretada sobre hechos actuales" (1983, p. 361) y Martín Vivaldi añade que se trata de "una información interpretativa y valorativa de los hechos noticiosos [...] donde se narra algo al propio tiempo que se juzga lo narrado" (1998, p. 128). Borrat (1989) destaca el estilo libre del autor o la posibilidad de usar recursos de la literatura; y Grijelmo (2001), la combinación entre información y visión personal del autor. Chillón (2014, p. 199) subraya que "el estilo de la crónica conjuga agilidad y eficacia periodísticas con elaboración literaria”, una libertad expresiva que promueve el 
"nexo de familiaridad" con el lector", por la periodicidad con que escribe el cronista y la especialización. Gomis (1991) distingue entre crónica de corresponsal (geográfica) y temática.

Más allá del parentesco entre crónica y reportaje, existen diferencias importantes en la voluntad de interpretar el contexto, derivadas de la vinculación temporal a los acontecimientos. En la crónica, prima la actualidad ( $\mathrm{Mu}$ ñoz González, 1994), hasta el punto de que información e interpretación son dos componentes inseparables (Yanes, 2006). El carácter cronológico (Martín Vivaldi, 1998; Gargurevich, 1982) y la presencia del autor como testigo que da fe de los hechos con "su particular forma de expresarse" (Yanes, 2006) resultan clave. Esto último garantiza "un relato rico en observaciones" (Gil Tovar, 1978, p. 18), permite "narrar cómo sucedió un determinado hecho y recrea la atmósfera en que se producen los sucesos” (Leñero y Marín, 1986, citados por Callegaro, Lago, Quadrini y Bragazzi, 2011, p. 14).

El reportaje flexibiliza el vínculo con la actualidad y, con ello, el tiempo que se puede invertir en su elaboración, lo cual repercute en la magnitud de la investigación, la posibilidad de incluir más fuentes o de ofrecer textos más extensos. En definitiva, busca captar una historia con todos sus detalles, con la precisión y contextualización necesarias (Samper, 2001; Hoyos, 2003b). Parratt señala que el reportaje "suele ahondar, e incluso, explicar y analizar, en hechos actuales pero no necesariamente noticiosos, cuyo autor goza de una mayor libertad estructural y expresiva” (2003, p. 35) y Yanes (2006b) pone de relieve la vocación de explicar los antecedentes y consecuencias. Chillón define el reportaje como un género discursivo complejo, por su "diversidad funcional, temática, compositiva y estilística”, el género con mayores posibilidades narrativas, capaz de incorporar y combinar múltiples procedimientos de escritura y de absorber "en parte o del todo" los demás géneros periodísticos y los literarios y artísticos (2014, pp. 253-254).

\section{Límites desdibujados}

La revisión de las características de la crónica y del reportaje permite observar que la expansión del término crónica en los últimos años ha impli- 
cado, en primer lugar, una atribución de propiedades características del reportaje, y en segundo lugar, un desanclaje de la actualidad. En este sentido, el uso actual de la etiqueta crónica — en parte del contexto latinoamericano- como sinónimo de un relato de largo aliento fundamentado en un reporteo en profundidad respondería, por las condiciones de producción y ejecución, a las de un reportaje. De ahí la extrema confusión que plantea, incluso, entre primeros espadas del campo periodístico. Entre quienes la asumen con naturalidad, como Juan Villoro, que presenta la crónica como "el ornitorrinco de la prosa" y subraya la importancia de la indagación, los datos o la polifonía de testigos (2012, pp. 577-581), o Villanueva Chang, que resalta la relevancia del reporteo, la escritura y la reflexión (2012, p. 603), y quienes se sorprenden del auge reciente del término, como Alberto Salcedo Ramos:

Empecé a ejercer el periodismo a mediados de los años ochenta. En aquel momento nadie le llamaba "crónica" a este tipo de historias, sino "reportaje". En algún momento [...] todo el mundo empezó a usarla. Ahora se ha puesto de moda. (citado por Brunetti, Luque y Orellana, 2015, p. 72)

De hecho, autores como Hoyos (2003b) y Samper (2001b) abogan por el término reportaje y aluden con la referencia crónica a los textos que entroncarían con el modernismo.

Del carácter reciente de estos cambios da fe el hecho de que, pese a la apuesta de la Fundación Nuevo Periodismo Iberoamericano por la marca "cronistas de Indias", ${ }^{11}$ el inspirador de la entidad, Gabriel García Márquez (2001), abogaba por el término reportaje para referirse a sus trabajos de largo aliento en la no ficción: ${ }^{12}$

11 La entidad, una de las impulsoras del periodismo literario en el ámbito latinoamericano, celebró en 2008 un congreso en Bogotá bajo el lema Nuevos Cronistas de Indias, con una segunda edición en México en 2012. Con motivo de esta última, el periodista Sergio Ramírez publicó en un artículo en el que daba razones de esta elección, remontándose al vínculo histórico con las crónicas de Heródoto o las de Indias.

12 En este mismo texto, el premio nobel de literatura de 1982 explicaba que sus obras con referencias a géneros periodísticos, pese a la denominación, se englobarían dentro de un género como el reportaje, tanto Crónica de una muerte anunciada como Noticia de un secuestro o Relato de un náufrago. 
Mi problema original como periodista fue el mismo de escritor: cuál de los géneros me gustaba más, y terminé por escoger el reportaje, que me parece el más natural y útil del periodismo. El que puede llegar a ser no sólo igual a la vida, sino más aún: mejor que la vida. Puede ser igual a un cuento 0 una novela con la única diferencia - sagrada e inviolable - de que la novela y el cuento admiten la fantasía sin límites pero el reportaje tiene que ser verdad hasta la última coma. Aunque nadie lo sepa ni lo crea.

La incomodidad con el sentido expansivo del término crónica y su vaguedad ha llevado a algunos autores no solo a abogar por designaciones alternativas, como periodismo literario o periodismo narrativo, sino, directamente, a mostrar su hartazgo por un uso inflacionista (Caparrós, 2015, pp. 48-49). Con todo, la controvertida nominación dista de ser exclusiva de la no ficción en castellano, como revela Many (1996, pp. 59), al remitir a la extensa lista de apelativos en inglés asociados a textos híbridos, en la frontera entre periodismo y literatura.

\section{Las tres identidades de la crónica}

La disección desarrollada en los epígrafes precedentes permite observar que, lejos de cualquier signo de univocidad, el término crónica alberga al menos tres identidades, que son el resultado de la influencia de los ámbitos en los que este concepto ha evolucionado a lo largo de la historia. Ecos de un pasado que se inicia con las crónicas grecorromanas y toma el relevo en las de Indias, que navega entre el periodismo y la literatura de la mano de los modernistas y que, con posterioridad, de lleno en el ámbito periodístico, se redefine como un género interpretativo, vinculado a la actualidad, o todo lo contrario, como la expresión más sofisticada de la narrativa de no ficción. Con semejante $\mathrm{ADN}$, no resulta extraño encontrar hasta tres personalidades diferentes que atienden al título de crónica. ${ }^{13}$ Aunque, en la práctica, las denominaciones son fru-

13 Samper diferencia cuatro tipos de crónicas: 1. las de los "historiadores de tono menor que relataron la conquista y colonia de las Indias"; 2. "los relatos breves, ágiles y sin pretensiones que contaban algún suceso del pasado”, con mucho contenido humano; 3. "cierto tipo de ensayos ligeros, de corte literario"; y 4. "una modalidad periodística que algunos profesores tratan de separar minuciosamente del reportaje" (2011, pp. 13-14). 
to de una confluencia de factores, a título exploratorio se ha optado por añadir un complemento a los tres tipos identificados, para visibilizar su espacio. Se han evitado los términos literario o periodístico, puesto que la hibridez impregna cada modalidad. El matiz se establece en detalles como la referencialidad, la autoría o la actualidad, ya sea una apuesta más ensayística (crónica de autor), de interpretación de la realidad inmediata (crónica de actualidad) o de sucesos más complejos (crónica de largo aliento) (figura 1).

Figura 1. Representación de las modalidades de crónica

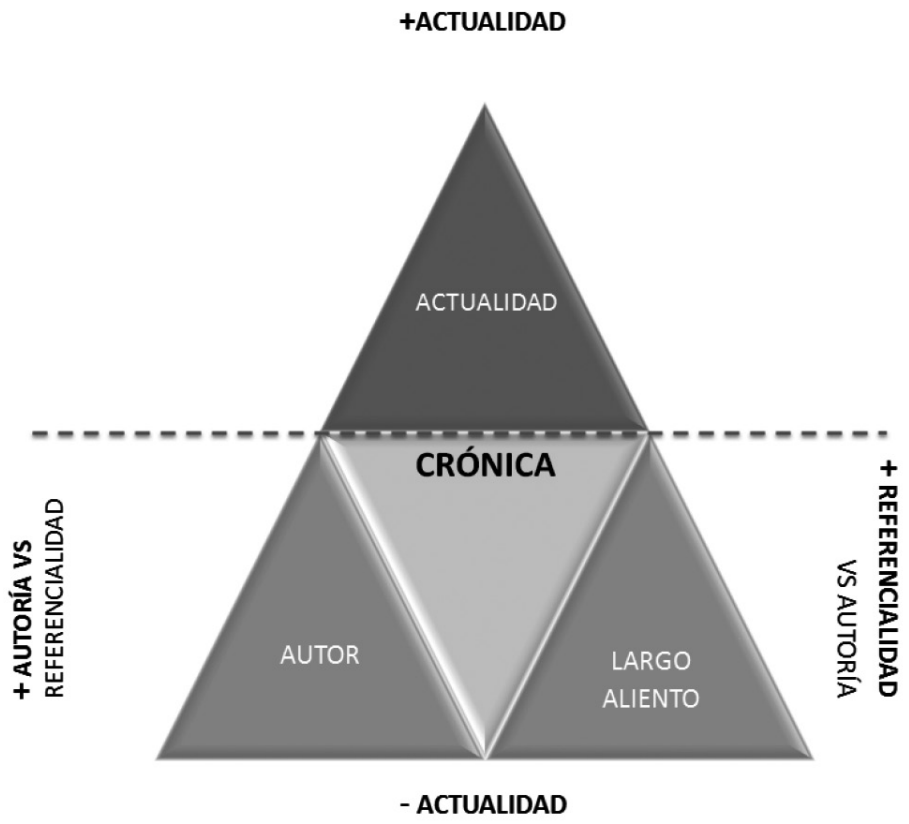

Fuente: Elaboración propia.

Atendiendo a los tres marcos que han modelado la identidad de la crónica como concepto plural, "categoría trigénica" (Carrera, 2016), se ha optado por situar en un eje vertical los tres polos de influencia (histórico, literario y periodístico) con diferentes parámetros explicativos, extraídos de las características que les han atribuido los autores referenciados. De este modo, se pretende definir la variedad de matices que caracterizan a los tres tipos de producciones identificadas como crónica (tabla 1). 


\section{Tabla 1. Características de las tres modalidades de crónica}

\begin{tabular}{|c|c|c|c|c|}
\hline & Parámetros & Crónica de autor & Crónica de largo aliento & Crónica de actualidad \\
\hline \multirow{3}{*}{ Polo histórico } & Temática & Zeitgeist & Social & Especializada \\
\hline & Posición del cronista & Observador-flâneur & $\begin{array}{l}\text { Investigador de la realidad } \\
\text { social }\end{array}$ & $\begin{array}{l}\text { Intérprete de unos } \\
\text { hechos }\end{array}$ \\
\hline & Objetivo & Testigo del tiempo & Análisis de fondo & Informar e interpretar \\
\hline \multirow{4}{*}{ Polo literario } & Autoría & Prestigio & Profesionalidad & Especialización \\
\hline & $\begin{array}{c}\text { Presencia del yo en } \\
\text { el texto }\end{array}$ & Explícita & Explícita-implícita & Implícita \\
\hline & $\begin{array}{l}\text { Importancia del } \\
\text { componente } \\
\text { expresivo }\end{array}$ & Máxima & Sustancial & Sustancial \\
\hline & Estructura & Libre & Libre & Cronológica \\
\hline \multirow{7}{*}{$\begin{array}{c}\text { Polo } \\
\text { periodístico }\end{array}$} & Referencialidad & Accesoria & Máxima & Máxima \\
\hline & $\begin{array}{c}\text { Vinculación con la } \\
\text { actualidad }\end{array}$ & Moderada & Flexible & Máxima \\
\hline & $\begin{array}{l}\text { Investigación de los } \\
\text { hechos }\end{array}$ & Innecesaria & Amplia & Acotada \\
\hline & $\begin{array}{c}\text { Presencia en el lugar } \\
\text { de los hechos }\end{array}$ & Innecesaria & Necesaria & Necesaria \\
\hline & Diversidad de fuentes & Innecesaria & Necesaria & Flexible \\
\hline & Extensión & Breve & Amplia & Breve-media \\
\hline & $\begin{array}{l}\text { Continuidad del } \\
\text { autor }\end{array}$ & Necesaria & Innecesaria & Necesaria \\
\hline
\end{tabular}

Fuente: Elaboración propia.

\section{Conclusiones}

La crónica parte de un relato y una mirada puestos al servicio de la interpretación de unos hechos. Con este equipaje, ha recorrido más de veinticinco siglos de historia y ha atravesado varios continentes, hasta abarcar una pluralidad de opciones que responden a este apelativo. Con el objetivo de aclarar ciertas confusiones y críticas cruzadas entre cultivadores de las distintas modalidades, se ha optado, en primer lugar, por deslindar los orígenes históricos, literarios y periodísticos e identificar una serie de parámetros atribuidos a cada uno de los polos de influencia; y en segundo lugar, por mostrar el peso de estos parámetros en los tipos de crónica identificados. Ello ha permitido visualizar una escala de matices imbricados en las tres modalidades, que explican el efecto de cercanía y distancia, el desconcierto que provoca el reconocimiento y extrañamiento de ciertos rasgos. 
En primer lugar, la crónica decantada hacia el ángulo literario, heredera de los modernistas y de la tradición costumbrista en el periodismo español, da prioridad a la escritura mientras relega la carga de referencialidad, que tiene un carácter secundario frente al prestigio o el reconocimiento del titular de la rúbrica. El autor se convierte en observador privilegiado que toma un rasgo de la actualidad como excusa, como punto de partida o recurso accesorio — no como un objetivo en sí mismopara trascenderlo, para desplegar su prosa en un texto que aspira a captar el espíritu del tiempo, en una línea ensayística próxima al articulismo de opinión. Esto tiene consecuencias importantes respecto de la producción periodística, que adquiere un carácter superfluo, irrelevante, cuando no criticado por constituir una especie de coartada, un aparataje que pretende mostrar lo inasequible.

En el segundo de los vértices, se situaría la crónica de actualidad, un género que en cierta manera se ha desdibujado en el periodismo de algunos países latinoamericanos, pero con una identidad sólida en el ámbito español (desde las crónicas deportivas a las de corresponsal, pasando por las parlamentarias), destinada a ofrecer la interpretación del acontecer inmediato, por parte de un cronista-testigo que dispone de la cualificación-especialización en un ámbito temático o geográfico, que le otorga autoridad para sustentar su análisis. En este caso, la escritura tiene una importancia sustancial, pero está supeditada al relato y la interpretación de unos hechos recientes, lo cual influye en su alcance.

Por último, se han identificado como crónicas de largo aliento aquellas producciones que, sin perder el carácter periodístico, se apartan de la inmediata actualidad, lo cual permite creaciones más extensas y elaboradas. Dadas sus características, esta acepción de crónica se solapa con la de reportaje, hasta el punto de atribuirles rasgos análogos. La investigación, la presencia en los escenarios y la entrevista en profundidad a las fuentes, todo aquello que representa el polo de atención periodística, prevalece como prioritario. La autoría viene, en este sentido, marcada por la profesionalidad, la habilidad para investigar un ámbito de la realidad social, analizarlo y ser capaz de ofrecer una interpretación a fondo. Pero, además de captar la complejidad, estas 
crónicas representan también un reto importante respecto de la escritura, a través de relatos de gran formato que combinan las exigencias de facticidad con la ambición narrativa que tradicionalmente acompaña a la ficción. La superposición reportaje/crónica, abrazada sin inconveniente por autores de distintos países latinoamericanos, resulta conflictiva, sin embargo, en otras tradiciones periodísticas de la región, y también en España, donde el término crónica se asocia con la acepción de actualidad.

\section{Referencias}

Aguilar, M., Darrigrandi, C., Méndez, M. y Viu, A. (eds.) (2014). Escrituras a ras de suelo: crónica latinoamericana del siglo XX. Santiago de Chile: Universidad Finis Terrae.

Alvar, C., Mainer, J. C. y Navarro, R. (1997). Breve historia de la literatura española. Madrid: Alianza.

Bernabé, M. (2010). Sobre márgenes, crónica y mercancía. Boletín, 15, 1-17.

Bernabé, M. (2014). Crónica, vanguardias y tecnologías: Roberto Arlt y sus ochocientas palabras por día. En Marcela Aguilar, Claudia Darrigrandi, Mariela Méndez y Antonia Viu (eds.), Escrituras a la ras de suelo: crónica latinoamericana del siglo XX (pp. 119-156). Santiago de Chile: Universidad Finis Terrae.

Bernal, M. (1997). La crónica periodística: tres aproximaciones a su estudio. Sevilla: Padilla Editores.

Borrat, H. (1989). El periódico, actor político. Barcelona: Gustavo Gili.

Brunetti, P. M., Luque, D., y Orellana, M. (2015). Volviendo sobre la crónica y las añejas tensiones entre periodismo y literatura. Questión, 48(1), 62-77. Recuperado de http://sedici.unlp.edu.ar/handle/10915/50439 
Cabrol, G. (2009). La crónica: un modo de narrar Latinoamérica. Ponencia presentada en VII Congreso Internacional Orbis Tertius de Teoría y Crítica Literaria, Centro de Estudios de Teoría y Crítica Literaria, Rosario, Argentina. Recuperado de http://sedici.unlp.edu.ar/ handle/10915/17412

Cairati, E. (2013). Periodismo narrativo peruano como territorio de la subalternatividad. Anales de Literatura Hispanoamericana, 42, 41-54.

Callegaro, A., Lago, C., Quadrini, M. y Bragazzi, F. (2011). La crónica latinoamericana como espacio de resistencia al periodismo hegemónico. Recuperado de http://humanidades.unlam.edu.ar/ descargas/4_A145.pdf

Caparrós, M. (2012). Por la crónica. En D. Jaramillo (ed.), Antología de crónica latinoamericana actual (pp. 607-612). Madrid: Alfaguara.

Caparrós, M. (2015). Lacrónica. Madrid: Círculo de Tiza.

Carrera, G. L. (2016). Para una línea evolutiva de la crónica en Latinoamérica: valor modélico del proceso venezolano. América. Cahiers $d u$ CRICCAL, 48. DOI: 10.4000/america. 1445

Carrión, J. (2012). Mejor que ficción: crónicas ejemplares. Barcelona: Anagrama.

Chillón, A. (2014). La palabra facticia: literatura, periodismo y comunicación. Barcelona: Universitat Autònoma de Barcelona, Universitat Jaume I, Universitat de València.

Cristoff, M. S. (comp.) (2006). Idea crónica. Buenos Aires: Beatriz Viterbo.

Cristoff, M. S. (17 enero 2009). Cierto modo de contar el mundo. En La Nación. Recuperado de http://www.lanacion.com.ar/1089503cierto-modo-de-contar-el-mundo 
Cristoff, M. S. (2014). La libertad es un campo minado. En Anfibia. Recuperado de http://www.revistaanfibia.com/ensayo/la-libertad-esun-campo-minado/

Darrigrandi, C. (2013). Crónica latinoamericana: algunos apuntes sobre su estudio. Cuadernos de Literatura, 17(34), 122-143.

Falbo, G. (2007). Introducción. En G. Falbo (ed.), Tras las huellas de una escritura en tránsito (11-19). Buenos Aires: Al Margen.

García Márquez, G. (2001). Sofismas de distracción. Sala de Prensa, 29(2). Recuperado de http://www.saladeprensa.org/art201.htm

Gargurevich, J. (1982). Géneros periodísticos. La Habana: Pablo de la Torriente.

Gil González,J. C. (2004). La crónica periodística. Evolución, desarrollo y nueva perspectiva: viaje desde la historia al periodismo interpretativo. Global Media Journal, 1(1). Recuperado de http://gmje. mty.itesm.mx/gil.html

Gil Tovar, F. (1978). Iniciación a la comunicación social. Bogotá: Ediciones Paulinas.

Gomis, L. (1991). Teoría del periodismo: cómo se forma el presente. Barcelona: Paidós Comunicación.

González, A. (1995). Crónica y cuento en el modernismo. En E. PupoWalker (coord.), El cuento hispanoamericano (pp. 155-170). Madrid: Castalia.

Grijelmo, Á. (2001). El estilo del periodista. Madrid: Santillana.

Hernández Fernández, O. (2008). Tiempo de Indias: crónicas e imágenes del nuevo mundo y la expresión literaria latinoamericana. Sapiens, $9(1), 213-235$. 
Herrscher, R. (2012). Periodismo narrativo: cómo contar la realidad con las armas de la literatura. Barcelona: Universitat de Barcelona.

Hoyos, J.J. (2003a). Escribiendo historias: el arte y el oficio de narrar en el periodismo. Medellín: Universidad de Antioquia.

Hoyos, J. J. (2003b). Literatura de urgencia. Medellín: Universidad de Antioquia.

Jaramillo, D. (2012). Antología de crónica latinoamericana actual. Madrid: Alfaguara.

Jiménez, J. O. (ed.) (1995). José Martí: ensayos y crónicas. Madrid: Anaya \& Mario Muchnick.

Kapuscinski, R. (2006). Viajes con Herodoto. Barcelona: Anagrama.

Many, P. (1996). Literary Journalism: Newspapers' Last, Best Hope. The Connecticut Review, 19(1), 59-69.

Marques de Melo, J. (1992). La crónica como género periodístico en la prensa luso brasileña e hispano-americana. Diálogos de la comunicación, 34. Recuperado de http://dialogosfelafacs.net/wp-content/ uploads/2015/34/34-revista-dialogos-la-cronica-como-generoperiodistico.pdf

Martín Vivaldi, G. (1998). Géneros periodísticos: reportaje, crónica, artículo. Análisis diferencial. Madrid: Paraninfo.

Martínez Albertos, J. L. (1983). Curso general de redacción periodística. Barcelona: Mitre.

Mateo, A. (2001). Crónica y fin de siglo en Hispanoamérica (del siglo XIX al XXI). Revista Chilena de Literatura, 59, 13-39. Recuperado de http://www.revistaliteratura.uchile.cl/index.php/RCL/article/ view/39019/40665 
Montes, A. (2013). Políticas y estéticas de representación de la experiencia urbana en la crónica contemporánea. Buenos Aires: Corregidor.

Moreno, M. (2005). Escritores crónicos. Página/12. Recuperado de http://www.pagina12.com.ar/diario/suplementos/radar/9-2425-2005-08-07.html

Moreno, M. (2007). Banco a la sombra. Buenos Aires: Sudamericana.

Moreno, M. (2010).La crónica rabiosa. Página/12. Recuperado de http://www. pagina12.com.ar/diario/verano12/23-139155-2010-01-28.html

Muñoz González, J. J. (1994). Redacción periodística. Salamanca: Librería Cervantes.

Oviedo, J. M. (1991). Historia de la literatura hispanoamericana. Madrid: Alianza.

Parratt, S. F. (2003). Introducción al reportaje: antecedentes, actualidad y perspectivas. Santiago: Universidad de Santiago de Compostela.

Parrat, S. F. (2008). Géneros periodísticos en prensa. Quito: Ciespal.

Poblete, P. (2013). Hibridez y tradición en la crónica latinoamericana contemporánea: los textos de Rafael Gumucio. Textos Hibridos: Revista de estudios sobre la crónica latinoamericana, 3(1). Recuperado de http://escholarship.org/uc/item/4z85s4w0

Poblete, P. (2014). La crónica periodístico-literaria contemporánea en Chile. Estudios sobre el Mensaje Periodístico, 20(2), 1165-1176.

Ramírez, S. (3 noviembre 2012). Los nuevos cronistas de Indias. En La Nación. Recuperado de http://www.lanacion.com.ar/1523193-losnuevos-cronistas-de-indias 
Ramos, J. (1989). Desencuentros de la modernidad en América Latina: literatura y política en el siglo XIX. México: Fondo de Cultura Económica.

Reguillo, R. (2007). Textos fronterizos: la crónica una escritura a la intemperie. En G. Falbo (ed.), Tras las huellas de una escritura en tránsito (pp. 41-50). Buenos Aires: Al Margen.

Rotker, S. (ed.) (1993). José Martí: crónicas. Antología crítica. Madrid: Alianza.

Rotker, S. (2005). La invención de la crónica. México: Fondo de Cultura Económica.

Samper, D. (2001). Antología de grandes reportajes colombianos. Bogotá: Aguilar.

Sefchovich, S. (2015). Cronistas de fin del siglo XX. Textos Híbridos: Revista de estudios sobre la crónica latinoamericana, 4, 1-19.

Vallejo, M. (1997). La crónica en Colombia: medio siglo de oro. Bogotá: Presidencia de la República.

Vallejo, M. (2006). A plomo herido: una crónica del periodismo en Colombia (1880-1980). Bogotá: Planeta.

Villanueva Chang, J. (2012). El que enciende la luz. En D. Jaramillo (ed.), Antología de crónica latinoamericana actual (pp. 583-606). Madrid: Alfaguara.

Villoro, J. (2012). La crónica, ornitorrinco de la prosa. En D. Jaramillo (ed.), Antología de crónica latinoamericana actual (pp. 577-582). Madrid: Alfaguara.

Viola, L. (2010). Entrevista a María Moreno. Página/12. Recuperado de http://www.pagina12.com.ar/diario/suplementos/las12/135916-2010-08-13.html 
Yanes, R. (2006). La crónica, un género del periodismo literario equidistante entre la información y la interpretación. Espéculo, 32. Recuperado de http://pendientedemigracion.ucm.es/info/especulo/ numero32/cronica.html

Yanes, R. (2006b). El reportaje, texto informativo aglutinador de distintos géneros periodísticos. Espéculo, 34. Recuperado de http://pendientedemigracion.ucm.es/info/especulo/numero34/reportaj.html 